\title{
TEORIA CRÍTICA E FORMAÇÃO DO INDIVÍDUO: CONSIDERAÇÕES SOBRE A ANÁLISE CRÍTICO-DIALÉTICA DA RELAÇÃO ENTRE SUBJETIVIDADE E OBJETIVIDDE NA CONTEMPORNEIDADE*
}

\author{
Maria Isabel Formoso Cardoso e Silva Batista**
}

\begin{abstract}
Resumo: Este texto objetiva traçar algumas considerações sobre a formação do indivíduo e refletir sobre a necessidade de uma análise crítica sobre os elementos e os processos formativos contemporâneos respaldada no método dialético, apoiado nos fundamentos da Teoria Critica da Sociedade e nos princípios psicanalíticos, a fim de que se possam apreender as contradições sociais presentes na relação sujeito-objeto/indivíduo-sociedade. Por meio da reflexão sócio histórica, inerente ao método dialético, o movimento histórico da realidade social é apreendido teórica e conceitualmente, conduzindo à compreensão da relação entre subjetividade e objetividade como reciprocamente mediada, tendo-se a subjetividade como fruto de um projeto histórico e paradoxal da civilização ocidental. Assim, analisar criticamente a formação do indivíduo na contemporaneidade significa considerar as tendências e as contradições desenvolvidas ao longo do processo histórico, que produziram certos elementos presentes no contexto social e cultural da atualidade, os quais se interligam e incidem diretamente sobre os processos formativos, de modo a determiná-los.
\end{abstract}

Palavras-chave: Teoria Crítica; Psicanálise; Método Dialético; Formação do Indivíduo; Relação Sujeito-Objeto

Resumen: Este texto objetiva trazar algunas consideraciones sobre la formación del individuo y reflexionar sobre la necesidad de un análisis crítico sobre los elementos y los procesos formativos contemporáneos respaldada en el método dialéctico, apoyado en los fundamentos de la Teoría Crítica de la Sociedad y en los principios psicoanalíticos, a fin de que se puedan aprehender las contradicciones sociales presentes en la relación sujeto-objeto / individuo-sociedad. Por medio de la reflexión socio histórica, inherente al método dialéctico, el movimiento histórico de la realidad social es percibido teórica y conceptualmente, conduciendo a la comprensión de la relación entre subjetividad y objetividad como recíprocamente mediada, teniendo la subjetividad como fruto de un proyecto histórico y paradójico de la civilización occidental. Así, analizar críticamente la formación del individuo en la contemporaneidad significa considerar las tendencias y las contradicciones desarrolladas a lo largo del proceso histórico, que produjeron ciertos elementos presentes en el contexto social y cultural de la actualidad, los cuales se interconectan e inciden directamente sobre los procesos formativos, para determinarlos.

Palabras claves: Teoría Crítica; el psicoanálisis; Método dialéctico; Formación del Individuo; Relación Sujeto-Objeto

* Parte da discussão proposta neste texto foi apresentada no X Congresso Internacional de Teoria Crítica: Tecnologia Violência e Memória, na Universidade Federal de São Carlos - UFSCar, em 2016.
** Graduada em Psicologia pela UNESP-Assis; Mestre em Educação Escolar pela UNESPAraraquara; Doutora em Psicologia Social pela PUCSP; Pós-Doutoranda do Programa de PósGraduação em Educação da UFSCar. Professora Associada da Universidade Estadual do Oeste do Paraná - UNIOESTE/Campus de Toledo. Docente do Programa de Pós-Graduação em Serviço Social PPGSS. E-mail: miformoso@hotmail.com

BATISTA, Maria Isabel Formoso Cardoso e Silva. Teoria crítica e formação do indivíduo: considerações sobre a análise crítico-dialética da relação entre subjetividade e objetividade na contemporaneidade. Revista Sul-Americana de Filosofia e Educação. Número 29: nov./2017-abr./ 2018, p. 85-101. DOI: https://doi.org/10.26512/resafe.v0i29.21008 
Diante das tendências atuais de formação dos indivíduos, torna-se premente refletir sobre a realidade $e$ sobre as condições objetivas e subjetivas que produzem e reproduzem essas tendências. Entretanto, para que tal realidade e tais condições se revelem à análise, essa reflexão não pode prescindir de um método que indague sobre as transformações $e$ as contradições presentes no sujeito e no objeto. Desse modo, este texto objetiva traçar breves apontamentos sobre as tendências e os elementos que compõem a formação dos indivíduos na contemporaneidade e discutir a necessidade de uma análise de tais elementos respaldada no método dialético, apoiado nos fundamentos da Teoria Critica da Sociedade e nos princípios psicanalíticos, a fim de que se possa apreender "o conjunto do movimento histórico" (LÖWY, 1995) e as contradições sociais presentes na relação sujeito-objeto/indivíduo-sociedade.

\section{Tendências contemporâneas da formação do indivíduo}

Refletir sobre as tendências atuais de formação do indivíduo significa colocar em foco os elementos do contexto social e cultural da atualidade, que se interligam e incidem diretamente sobre os processos forma- tivos, de modo a determiná-los. Tais elementos, essenciais à manutenção das condições objetivas vigentes, foram gestados nas relações de produção desenvolvidas historicamente, as quais tiveram por base as contradições da sociedade burguesa, intensificadas, segundo Horkheimer e Adorno (1973), a partir de seu desenvolvimento econômico e político.

Sendo assim,

Com a entronização do princípio de concorrência, a eliminação dos limites das ordens correlativas $e$ o início da revolução técnica na Indústria, a sociedade burguesa desenvolveu um dinamismo social que obriga o indivíduo econômico a lutar implacavelmente por seus interesses de lucro, sem se preocupar com o bem da coletividade. $\mathrm{O}$ impulso consciente para atuar nesse sentido foi favorecido pela ética protestante e o conceito burguês capitalista de dever. O ideal antifeudal da autonomia do indivíduo compreendia a autonomia da decisão política dos indivíduos; no contexto econômico, porém, transformou-se numa ideologia que exigia a manutenção da ordem vigente $e$ o constante recrudescimento da capacidade de realização produtiva. Assim, para o indivíduo totalmente interiorizado, a realidade convertese em aparência e a aparência em realidade. Ao proclamar como absoluta a sua existência solitária, dependente da sociedade $e$, inclusivamente, tolerada e revogável por esta, torna-se frase absoluta (...). O 
meio ideal da individuação, a Arte, a Religião, a Ciência, retrai-se $e$ depaupera-se como posse privada de alguns indivíduos, cuja subsistência só ocasionalmente é garantida pela sociedade. A sociedade que estimulou o desenvolvimento do indivíduo, desenvolve-se agora, ela própria, afastando de si o indivíduo, a quem destronou. (HORKHEIMER E ADORNO, 1973, p. 55)

As necessidades objetivas de desenvolvimento econômico das sociedades ocidentais possibilitaram a construção histórica do assim chamado "indivíduo burguês", cuja formação cultural e autonomia eram condições sine qua non para o progresso econômico e político da sociedade capitalis-

1 "Paralelamente, o desaparecimento das formas de propriedades feudais e comunais, a apropriação privada dos meios de produção e a apropriação individual do próprio corpo - que liberto das obrigaçóes e separado da terra convertia-se em força de trabalho - asseguravam as bases econômicas da existência individual independente. Finalmente, a competição no mercado de bens e de trabalho projetava a individualização como ideal e précondição para a realização do sujeito no contexto da vida em sociedade" (FIGUEIREDO, 2008, p. 20). Mas, ao mesmo tempo em que o desenvolvimento econômico da sociedade capitalista criava possibilidades à realização do ideal anti-feudal da individuação, esta, por seu turno, estava atrelada às próprias condições materiais dos sujeitos sociais na Modernidade. Desse modo, conforme Adorno (1971), a autonomia tinha um substrato econômi$\mathrm{co}$, o que permitiu à classe burguesa diferenciar-se, no processo histórico, das demais (proletários, campesinos e artesãos) e chegar ao poder: "Cuando la burguesia se apoderó politicamente del Poder em la Inglaterra del siglo XVII y en la Francia del XVIII, estaba económicamente más desarrollada que la feudalidad y, desde luego, también en cuanto a consciência." (p. 239-40) ta ("quanto más lúcido fuese el singular, más lúcido seria el todo" (ADORNO, 1971, p. 239)). No entanto, como a individuação se fez à custa da expropriação (material $e$ subjetiva) do outro (FIGUEIREDO, 2008) e, também, à custa da própria individualidade (singularidade/diferenciação) do sujeito (HORKHEIMER E ADORNO, 1985), esse processo acaba por implicar no desenvolvimento de relações instrumentais e calculistas, e na perseguição irracional e egoísta de interesses particulares. $O$ ideal iluminista $e$ liberal de singularidade, privacidade, liberdade e autonomia individual - erigido desde o início da Modernidade e fortalecido, nos séculos XVIII e XIX, a partir das demandas de desenvolvimento econômico da sociedade capitalista ocidental e com a ascensão da classe burguesa ao poder - converteu-se, assim, na necessidade objetiva do controle subjetivo e ideológico dos indivíduos; o traço de liberdade e de espontaneidade que caracterizava a formação cultural moderna cedeu lugar à instrumentalidade, que passou a conjugar controle e integração social ao princípio de troca ${ }^{2}$.

2 "El momento de espontaneidad, tal como fue glorificado por última vez en las teorías de Bergson y la obra novelesca de Proust, y tal como caracteriza la formación en cuanto algo distinto de los mecanismos de dominio social de la naturaleza, se descompone a la chillona luz de la examinabilidad. Frente al dicho práctico, en general la formación no se puede adquirir: la 
Nesse sentido, a formação do indivíduo na contemporaneidade não é, senão, a materialização das tendências históricas à integração dos sujeitos sociais ao todo, incrementadas com o desenvolvimento do liberalismo, do capitalismo concorrencial e do processo de formação cultural do indivíduo burguês. Tal integração, historicamente firmada sobre as demandas - ao mesmo tempo, interdependentes e antagônicas - de autonomização dos indivíduos e de desenvolvimento econômico-político das sociedades ocidentais, revela, assim, a dialética presente na formação do indivíduo burguês e o lastro paradoxal em que se funda a individualidade moderna.

De acordo com Horkheimer e Adorno (1985, p. 145-146),

adquisición y la mala posesión serían una sola cosa; mas, precisamente porque se niega a la voluntad, está envuelta en la culpable armonía del privilegiado: sólo no necesita adquirirla ni poseerla quien de todos modos la posea ya; y de esta suerte cae en la dialéctica de la libertad y la falta de libertad: como herencia de la antigua falta de libertad tendría que hundirse, siendo como es imposible con una libertad meramente subjetiva, mientras persistan objetivamente las condiciones de la falta de libertad. (...) la vida, modelada hasta en sus últimas ramificaciones por el principio de la equivalencia, se agota en la reproducción de sí misma, en la reiteración del sistema, y sus exigencias se descargan sobre los singulares tan dura y despóticamente, que cada uno de éstos ni puede mantenerse firme contra ellas como conductor por sí mismo de su propia vida, ni experimentarlas como una sola cosa con su condición humana." (ADORNO, 1971, p. 250)
A cultura de massas revela assim o caráter fictício que a forma do indivíduo sempre exibiu na era da burguesia, e seu único erro é vangloriar-se por essa duvidosa harmonia do universal $e$ do particular. O princípio da individualidade estava cheio de contradições desde o início. Por um lado, a individuação jamais chegou a se realizar de fato. (...) Todo personagem burguês exprimia, apesar de seu desvio e graças justamente a ele, a mesma coisa: a dureza da sociedade competitiva. O indivíduo, sobre o qual a sociedade se apoiava, trazia em si mesmo sua mácula: em sua aparente liberdade, ele era o produto de sua aparelhagem econômica e social. (...) Ao mesmo tempo, a sociedade burguesa também desenvolveu, em seu processo, o indivíduo. Contra a vontade de seus senhores, a técnica transformou os homens de crianças em pessoas. Mas cada um desses progressos da individuação se fez à custa da individualidade em cujo nome tinha lugar, e deles não sobrou senão a decisão de perseguir apenas os fins privados. O burguês cuja vida se divide entre o negócio $e$ a vida privada, cuja vida privada se divide entre a esfera da representação $e$ a intimidade, cuja intimidade se divide entre a comunidade malhumorada do casamento e o amargo consolo de estar completamente sozinho, rompido consigo e com todos, já é virtualmente o nazista que ao mesmo tempo se deixa entusiasmar e se põe a praguejar, ou o habitante das grandes cidades de hoje, que só pode conceber a amizade como social contact, como o contacto social de pessoas que não 
se tocam intimamente. [grifos dos autores]

A individuação erige-se, assim, desde a Modernidade, sobre a crescente irracionalidade do sistema social, que precisa, contraditoriamente, afirmar e negar o indivíduo (a este se torna necessário "perder-se para se conservar" (HORKHEIMER e ADORNO, 1985, p. 57)). Desse modo, tem-se a subjetividade como o resultado de um projeto histórico $e$ paradoxal da civilização ocidental. Tal projeto histórico, segundo Crochík (1998, p. 71), "se é determinado pelas condições concretas de vida, aponta, ao mesmo tempo, para a superação destas condições concretas, para que o indivíduo se assenhore delas, isto é, seja dono de seu destino". Assim, a busca da autonomia individual pressupõe a superação das condições objetivas, da cultura, mas, ao mesmo tempo é determinada por essa, ou seja, "a cultura é meio para a individuação" (idem). A formação do indivíduo - que, segundo Adorno e Horkheimer (1971), implica em adaptação à cultura $e$, ao mesmo tempo, em transposição dessa adaptação e, consequentemente, transformação do existente - somente pode se dar pela experiência de tensão do sujeito com o objeto, onde o primeiro envolve-se, incorpora, apropria-se e diferencia-se do segundo, tornando este, cultura (objetividade) subjetivada. Nesse sentido, a efetivação desse projeto histórico de formação do indivíduo (autonomização/individuação) exigia essa relação de tensão entre sujeito e objeto (indivíduo e sociedade), na qual pudesse haver o envolvimento e, ao mesmo tempo, o reconhecimento da diferenciação entre ambos.

Mas, se, de um lado, o processo de individuação denota a (necessária) tensão entre sujeito $e$ objeto (indivíduo $e$ sociedade); de outro, essa tensão, em meio ao desenvolvimento econômico das forças produtivas, não resultou em incremento da resistência e da autonomia individual, mas sim em fratura entre o indivíduo $e$ a sociedade. Se, conforme Horkheimer e Adorno (1985, p. 144), "Outrora, a oposição do indivíduo à sociedade era a própria substância da sociedade" - pois nessa "oposição" residia todo seu esforço para individuar-se, racionalizar-se, formarse, enfim, e era nesse processo em que também se dava o desenvolvimento da própria sociedade -, então, tal fratura, historicamente articulada e desenvolvida no bojo das relações sociais de produção, acaba implicando no esvaziamento dessa 
relação e no reverso da autonomia, ou seja, na fragilização do indivíduo, que, desamparado pela própria sociedade que outrora o entronizara, vê-se forçosamente obrigado a identificar-se e a integrar-se a ela como forma de minimizar o sentimento de aniquilação social e psíquica: "Todos têm que mostrar que se identificam integralmente com o poder de quem não cessam de receber pancadas" (idem).

Assim, em virtude da enorme pressão social projetada desde a Modernidade sobre o indivíduo, o produto histórico desse processo de formação é sua integração ao todo social; o indivíduo, fragilizado e heteronomamente (de)formado, passa a ser facilmente e diretamente cooptado pelas forças sociais. A mediação outrora exercida pelas instituições sociais - as quais se colocavam perante o indivíduo como representação da autoridade ${ }^{3}$, como referência cultural e co-

3 Por mais problemática que a autoridade (representada pelas instituições sociais) fosse, em relação à formação cultural dominante até o século XIX, ainda se concentrava sobre ela - conforme já discutido anteriormente em outro texto (BATISTA, 2015) - a função de mediação entre o indivíduo $e$ a cultura. "A autoridade desempenhava papel fundamental no processo de construção do eu, pois realizava a mediação entre o sujeito $e$ a cultura (tradição, valores, concepções, princípios, conteúdos transmitidos socialmente). É no 'confronto' com esse outro, representado pela autoridade, que é possibilitado ao sujeito desenvolver sua autonomia. Assim, esse confronto, para além da transmissão cultural transgeracional que ele opera, significa a experiência relacional do mo o não-idêntico (diferente) ${ }^{4}$ - perde sua força na sociedade de monopólios, deixando de promover experiências de enfrentamento do sujeito com a realidade (objeto). O esforço de individuação é substituído pelo esforço de imitação e integração social; o mimetismo se coloca no lugar da experiência com o objeto; a mera adaptação não deixa lugar à resistência. Frente à integração social, a diferenciação - resultado do processo de individuação e telos da formação cultural - sucumbe ao princípio totalitário ("A semelhança perfeita é a diferença absoluta. (...) Cada um é tão-somente aquilo mediante o que pode substituir todos os outros: ele [o homem] é fungível, um mero exemplar." (HORKHEIMER e ADORNO, 1985, p. 136)). Limitando-se à imitação e à mera adaptação, a formação acaba por se reduzir a uma semiformação ou pseudo-

sujeito com o mundo (com o não-idêntico), que lhe permite adaptar-se e resistir, identificar-se $e$ diferenciar-se, enfim, formar-se como indivíduo." (BATISTA, 2015, p. 25)

4 O não-idêntico (o outro; o não-eu) é, para Freud (1996) e Adorno (2006), fundamental ao processo de autonomização do sujeito, pois, na relação com este, obriga-o à diferenciação à medida que, representando a realidade, a cultura (objeto), confronta-se com ele (sujeito), o qual é colocado diante de duas possibilidades: ou resistir à fusão com o objeto e diferenciar-se dele (formação/individuação), ou sucumbir e integrar-se a ele (semiformação/adaptação). Sendo assim, pode-se dizer, de certa forma, que a diferença é ponto de partida e de chegada da formação do indivíduo. 
formação (ADORNO (1971); HORKHEIMER e ADORNO (1985)).

La pseudoformación no se confina ya meramente al espíritu, sino que adultera la vida sensorial; y responde a la cuestión psicodinámica de cómo pueda resistir el sujeto bajo una racionalidad que, en definitiva, sea ella misma irracional. En tanto que se cancelan los momentos de diferenciación - originariamente sociales - en que residía la formación, pues formación cultural y estar diferenciado son propiamente lo mismo, en lugar suyo prospera un sucedáneo. La perennizante sociedad del status absorbe los restos de la formación y los transforma en emblemas de aquél (...)" (ADORNO, 1971, p. 251)

Diante desse contexto, a (semi)formação em curso na contemporaneidade pode, de acordo com estudo realizado por Batista (2008) relativo à formação da juventude no capitalismo tardio, ser caracterizada pelos seguintes elementos: intensa fragilização egóica; necessidade de submissão à autoridade idealizada (heteronomia) $e$ de identificação com a agressividade nela presente; ausência de consciência moral e traços sadomasoquistas; regulação pelo princípio hedonista-individualista; exacerbação da lógica instrumental/tecnicista; frieza; tendência à indiferenciação. Esses elementos promovem uma integração artificial dos indivíduos à cultura e uma falsa identificação entre eles, e destes com a autoridade (idealizada); e ao aderirem às demandas objetivas, reforçam mecanismos psíquicos primitivos relacionados à necessidade de submissão à autoridade. As constantes pressões, ameaças e frustrações que sofrem, levam os indivíduos à sensação de desamparo e de desencantamento com o mundo $e$ os predispõem a introjetar a crueldade da própria sociedade, incrementando os traços narcisistas e sadomasoquistas de personalidade e obstando o desenvolvimento de sua consciência moral. Os mecanismos sociais de integração reforçam, portanto, a irracionalidade dos indivíduos, mantendo suprimidas suas forças de resistência individual $e$ suas possibilidades de autonomia, conduzindo-os à regressão e à barbárie.

A pressão social sobre o indivíduo, exercida pelos mecanismos ideológicos, impede que as contradições sociais sejam percebidas por ele. Desse modo, a semiformação vai além da deformação da consciência individual e coletiva e do mero falseamento de ideias (falsa consciência) - o que, diga-se de passagem, era justamente o que caracterizava a formação no contexto da ideologia liberal; hoje, porém, ela já não mais atua sobre o pensamento $e$ sobre a consciência racional dos indivíduos, mas 
atua junto aos elementos irracionais e "dispositivos" sensoriais desses, alterando e danificando sua percepção sobre a realidade (ADORNO (1971); HORKHEIMER e ADORNO (1973)). Diante da irracionalidade vigente, já não há mais nenhuma necessidade de qualquer esforço racional da consciência ou do pensamento para que o indivíduo reflita sobre a realidade (processo no qual se realizava a experiência [formativa] de enfrentamento com o objeto) e se compreenda em relação a ela, pois tudo já está dado (constatado, patente), sendo-lhe apresentado como natural ${ }^{5}$.

Assim, enquanto, no liberalismo, o pensamento, ainda que falseado e obscurecido pela lógica social (justificação das contradições sociais), permitia ao sujeito, mediante certo esforço racional, desvelar a realidade e suas contradições; no capitalismo tardio, frente à total ausência de um sentido racional da realidade $e^{6}$, consequentemente,

5 Mesmo que essa realidade não faça qualquer sentido ao indivíduo, torna-se impensável a ele, diante dessa "naturalização" do aparente, seu questionamento sobre essa falta de sentido, uma vez que isso o impossibilitaria de tomar parte do todo, e o levaria à exclusão social, tornando-se um "outsider" (HORKHEIMER e ADORNO, 1985, p. 140), sobre o qual recairia o ônus da denúncia da irracionalidade do sistema social.

6 Segundo Horkheimer e Adorno (1973; 1985), Adorno (1971) e Amaral (1997), a ausência desse sentido reside justamente na conciliação forçada entre universal e particular, entre público e privado. Desse modo, a "formação" fundada na ideologia a um processo de desencantamento do mundo, o sujeito já não se encontra em condições de ir além do objeto e, portanto, de desvelar suas contradições, pois tudo se converte, totalitariamente, em aparência e no "sempre-o-mesmo"; não há espaços para as contradições, para o diferente daquilo que necessariamente os indivíduos devem perceber e acreditar, nem para aquilo que escapa aos cálculos da administração planejada da sociedade. A "realidade dada (...) converte-se em ideologia de si mesma" (HORKHEIMER e ADORNO, 1973, p. 203), em máscara de si mesma, em sua própria aparência.

A falsa consciência de hoje, socialmente condicionada, já não é espírito objetivo, nem mesmo no sentido de uma cega e anônima cristalização, com base no processo social, pelo contrário, trata-se de algo cientificamente adaptado à sociedade. Essa adaptação realiza-se mediante os produtos da indústria cultural; como o cinema, as revistas, os jornais ilustrados, rádio, televisão, literatura de best-seller dos mais variados tipos, dentro do qual desempenham um papel especial as biografias romanceadas. (...) todos esses elementos e caracteres estão hoje

totalitarista vigente não abre espaço ao particular, ao singular, ao diferente; tudo deve ser organicamente coeso, conformado e integrado ao todo, não há mais "lacunas de socialização", por meio das quais um passo autônomo poderia ser dado. 
subordinados, em seu conjunto, a uma direção orgânica que converteu o todo num sistema coeso. Nenhuma fuga é tolerada, os homens estão cercados por todos os lados e as tendências regressivas, já postas em movimento pelo desenvolvimento da pressão social, são favorecidas pelas conquistas de uma psicologia social pervertida, ou, como corretamente se chamou essa prática, de uma psicanálise às avessas. (idem, p. 200-201)

Tal desencantamento é sentido pelo indivíduo diante da rigidez do esquematismo das relações sociais e dos mecanismos de integração, os quais the geram a impossibilidade de uma outra percepção sobre a realidade e de, em última instância, sua transformação. Essa impossibilidade é levada a efeito porque a própria ideologia contemporânea, que se apresenta como a "verdadeira aparência" do real (mentira manifesta) e como "a própria imagem ameaçadora do mundo" (idem, p. 203), apela ao hiper-realismo (um pseudo-realismo ${ }^{7}$ ) como forma de coagir moral e psiquicamente os indivíduos, fragilizando-os e induzindo-os à adesão.

\footnotetext{
7 "Quanto mais os bens culturais assim elaborados forem proporcionalmente ajustados aos homens, tanto mais estes se convencem de ter encontrado neles o mundo que lhes é próprio." (HORKHEIMER e ADORNO, 1973, p. 202)
}

Para resumir numa só frase a tendência inata da ideologia da cultura de massa, seria necessário representá-la numa paródia da frase: "Converte-te naquilo que és", como duplicação e super-ratificação da situação já existente, o que destruiria toda a perspectiva de transcendência e de crítica. O espírito socialmente atuante e eficaz limita-se, aqui, a pôr, uma vez mais, diante dos olhos dos homens, o que já constitui a condição da sua existência, ao mesmo tempo em que proclama o existente como sua própria norma, e, assim, confirma-os e consolida-os na crença, carente de verdadeira fé, em sua pura existência. (idem, p. 202-203)

Evidencia-se, assim, o que Adorno (1971) havia ponderado em relação às tendências formativas no capitalismo pósconcorrencial: sua inevitável conexão com a regressão dos homens ("la seudoformación cultural se asienta parasitariamente en el cultural lag" (p. 253)). Desse modo, as configurações do real (do objeto) atrelam-se intimamente às configurações psíquicas dos sujeitos. Na sociedade atual, a regressão das consciências é, ao mesmo tempo, o resultado do processo semiformativo e seu principal sustentáculo, retroalimentando-o, e impedindo-lhes o descortino dos processos ideológicos e das contradições sociais.

\footnotetext{
${ }^{8}$ Atraso cultural
} 
Mas, se as contradições sociais não podem ser diretamente percebidas e desveladas pelo próprio indivíduo, elas podem ser apreendidas nele, a partir de sua subjetividade e das contradições nela presentes; tendo-se em vista que o indivíduo deve ser compreendido em sua relação de reciprocidade com a sociedade, segundo a qual esta é meio de formação dos sujeitos e produto da relação entre eles, e o sujeito, cultura subjetivada e natureza não dominada.

\section{A análise crítica das tendências formativas}

É, pois, na análise desta relação entre indivíduo e sociedade - e em termos epistemológicos, entre sujeito e objeto - que se pode apreender o processo formativo em curso $e$, dialeticamente, tanto os limites que ele coloca à individuação, como as contradições sociais nele presentes, as quais expressam, paradoxalmente, as possibilidades de diferenciação e, portanto, de autonomia.

Sendo assim, "(...) a sociedade é a constituinte básica da subjetividade" (CROCHIK, 1998, p. 83) e a individuação a formação da subjetividade, por assim dizer - somente é possível quando há um reconhecimento da equivocidade entre sujeito e objeto, que pressupõe uma separação entre ambos, o que permite ao sujeito pen- sar-se como algo distinto do objeto, mas, dialeticamente, mediado e determinado por esse, do mesmo modo que o objeto encontra-se mediado pelo sujeito. Segundo Adorno (1995), essa separação é, ao mesmo tempo, "real e aparente", verdadeira e falsa, pois essa diferenciação do sujeito em relação ao objeto é mediada, dialeticamente, por uma relação de reciprocidade entre ambos: a tensão resultante da cisão entre sujeito e objeto é mantida, pois apesar do reconhecimento da diferenciação, há o reconhecimento do sujeito no objeto. Nesse sentido, essa diferenciação deve significar possibilidade de comunicação entre esses dois polos, "a comunicação do diferenciado", conforme Adorno (1995), onde haja de fato medição recíproca (e não supremacia de um sobre o outro), implicando numa "relação de paz" entre ambos: "Paz é um estado de diferenciação sem dominação, no qual o diferente é compartilhado" (p. 184). Portanto, essa "relação de paz" pressupõe uma relação dialética entre sujeito e objeto, na qual a primazia do objeto deve estar contemplada. A esse respeito Adorno (1995) propõe um "segundo giro copernicano", segundo o qual o sujeito deve vol-

\footnotetext{
${ }^{9} \mathrm{O}$ primeiro giro copernicano foi, de acordo com Adorno (1995), proposto por Kant ('intentio obliqua'), segundo o qual o sujeito (transcendental $e$ autônomo) apreende o objeto a partir suas
} 
tar-se sobre si mesmo para perceber-se como objeto, para apreender-se objetivamente como cultura apropriada, mediada pela subjetividade (que, por sua vez, também é objetividade). Essa lógica do objeto implica na compreensão da subjetividade como "configuração do objeto"; ela também reconhece o quanto o objeto é mediado pelo sujeito, embora aquele "não está tão absolutamente referido ao sujeito como o sujeito à objetividade" (ADORNO, 1995, p. 187).

Assim,

“(...) a primazia do objeto significa que o sujeito é, por sua vez, objeto em um sentido qualitativamente distinto e mais radical que o objeto, porque ele, não podendo afinal ser conhecido senão pela consciência, é também sujeito (...). A primazia do objeto é a 'intentio obliqua' da 'intentio obliqua', não a requentada 'intentio recta'; o corretivo da redução subjetiva, não a denegação de uma participação subjetiva." (ADORNO, 1995, p. 187-188)

Torna-se evidente a prevalência de uma lógica do objeto que não recorre de modo algum à negação do sujeito, mas, ao contrário, o apreende como determinado materialmente, objetivamente, afirmando-o, por isso mesmo, como sujeito: a objetivida-

próprias categorias, não podendo pensar a coisa em si. de é mais do que referência, é condição para o sujeito subjetivar-se e objetivar-se.

"Se se quiser, entretanto, alcançar o objeto, suas determinações ou qualidades subjetivas não devem ser eliminadas: isso contradiria, precisamente, a primazia do objeto. Se o sujeito tem um núcleo de objeto, então as qualidades subjetivas do objeto constituem, com ainda maior razão, um momento do objetivo. Pois o objeto torna-se algo somente enquanto determinado. Nas determinações que aparentemente o sujeito apenas lhe agrega, impõe-se a própria objetividade do sujeito (...)"(ADORNO, 1995, p. 188)

Sendo assim, analisar essa relação entre sujeito e objeto é por em evidência seu caráter histórico, ou seja, a compreensão histórica de como o sujeito e o objeto se colocam um perante o outro e de que modo ocorrem suas mediações. Essa reflexão permite identificar como são constituídas histórica e socialmente as relações entre objetividade e subjetividade, denunciando, por conseguinte, tanto as contradições sociais que permeiam tais relações, como as contradições presentes no próprio conhecimento e em sua relação com a práxis. Desse modo, torna-se possível apreender as descontinuidades em que se inscrevem essa relação: uma relação de "comunicação do diferenciado" em que, como no caso da 
relação entre sujeito e objeto, teoria e práxis não se identificam de forma imediata, nem são absolutamente distintas ${ }^{10}$.

Em seu texto sobre a relação entre Psicologia e Sociologia, Adorno (1986), discute a necessidade de investigação das condições subjetivas da irracionalidade objetiva ("La irracionalidade del sistema racional se manifesta en la psicología del sujeto cautivo" (p. 42), ou ainda, "Que la aptitud específicamente psicológica contenga casi siempre un componente irracional, en todo caso antisistemático, no es tampoco una casualidad psicológica, sino que se deriva del objeto, de la irracionalidad separada como complemento de la ratio dominante." (p. 44)).

Por isso, torna-se necessária a crítica aos elementos contemporâneos da formação que obstam as possibilidades de reflexão e autonomia dos indivíduos. A análise sobre a formação atual (e, portanto, sobre os processos contemporâneos de subjetivação) pode revelar as condições sócio históricas que têm mediado a produção $e$ a re-

\footnotetext{
10"Não há uma senda contínua que conduza da teoria à práxis (...). Mas a teoria pertence ao contexto geral da sociedade e é, ao mesmo tempo, autônoma. Apesar disto, nem a práxis transcorre independentemente da teoria, nem esta é independente daquela (...). O dogma da unidade entre teoria e práxis é (...) adialético: ele capta simples identidade ali onde só a contradição tem chance de ser frutífera." (ADORNO, 1995, p. 227)
}

produção de certa racionalidade objetiva em que se fundamentam os processos formativos; mais do isso, por meio dessa análise podem-se vislumbrar as contradições objetivas (e nelas, as "brechas" históricas para a transformação social), pois elas se encontram presentes no próprio indivíduo (em sua irracionalidade subjetiva); assim, paradoxalmente, as possibilidades de resistência estão refletidas na irracionalidade subjetiva, que delatam as contradições sociais e expressam a tensão entre indivíduo $e$ sociedade, favorecendo a transformação social.

No entanto, tentativas de transformação das condições existentes não mediadas pela reflexão crítica são inócuas e ideológicas, convertendo-se em pseudoatividade, podendo conduzir ao seu contrário: a intensificação dos mecanismos sociais de integração. A teoria do conhecimento tem lançado-mão de uma lógica formal fundamentada principalmente em uma lógica do sujeito e na negligência da comunicação entre sujeito e objeto, esvaziando a relação entre conhecimento/teoria e práxis. O formalismo, construído ao longo da história da civilização ocidental $e$ fortemente presente no pensamento científico, impõe modos de ser e de existir que impedem o desenvolvimento da experiência do sujeito perante a obje- 
tividade. Isso se reflete sobremaneira na relação teoria-práxis, que se torna cada vez mais imediata e irrefletida, marcada por uma espécie de pragmatismo, mediante o qual o pensamento ou a teoria perde seu caráter crítico e a práxis constitui-se em uma "práxis ilusória", "falsa práxis" ou ainda em um ativismo "vazio de conceito" (ADORNO, 1995).

Em contraposição à tendência formalista, situa-se a lógica dialética, demarcada pela lógica do objeto, não no sentido de sua supervalorização, mas sim da assunção de suas qualidades subjetivas ${ }^{11}$. São na própria análise e na compreensão do objeto de forma imanente e transcendente que essa lógica se desenvolve, tornando possível, a partir daí, a elaboração de conceitos miméticos, a produção de categorias a partir da objetividade do próprio objeto. Da mesma forma, é por meio dessa teoria dialética da objetividade que se pode apreender a historicidade e a objetividade presente na subjetividade.

\footnotetext{
11“(...) somente quando não se elimina do objeto as suas qualidades subjetivas, quando se as reconhece, é que se pode realmente experienciar o objeto, evitando assim a sua fetichização. A identificação do indivíduo com esses fragmentos o torna, por sua vez, também fragmentado e incapaz de auto-reflexão crítica. A emancipação do homem implica a eliminação radical do fetichismo do objeto." (SEVERIANO, 2001, p.112)
}

Desse modo, assevera Crochík (1998, p. 44), "o método para se estudar a subjetividade deve ser, portanto, o que leva a procurar o indivíduo nas marcas da sociedade"; aquele que, utilizando-se da lógica dialética e da teoria crítica da sociedade, possa penetrar na complexidade da relação entre subjetividade e objetividade, trazendo à tona suas contradições e contribuindo com uma revisão crítica da noção de indivíduo/sujeito.

Para Adorno (1986), a investigação das condições subjetivas da irracionalidade objetiva não pode prescindir da articulação entre uma "psicologia social analiticamente orientada"12 e uma teoria social de base crítica, voltadas ao exame crítico da realidade. Esse duplo movimento de análise (e não a fusão entre conceitos psicológicos $e$ sociológicos) permite entender dialeticamente o indivíduo, a sociedade e a relação entre ambos, apreendendo "las condiciones subjetivas de la irracionalidad objetiva" (p. 36).

Por meio da análise dialética da cisão indivíduo-sociedade, é possível percebermos suas contradições: se, de um lado, os homens já não se reconhecem como parte

\footnotetext{
12 Para Adorno (1986) a psicanálise freudiana seria, por excelência, a teoria psicológica mais adequada à análise profunda dos mecanismos psicológicos que sustentam a sociedade capitalista.
} 
de um todo comum e se isolam cada vez mais em suas supostas "individualidades" como mônadas, de outro, têm cada vez menos consciência da mediação social a que estão submetidos e que, paradoxalmente, reforça o isolamento entre eles, aprofundando a fratura entre os mesmos e a sociedade. Desse modo, já não percebem o quanto sua subjetividade foi apropriada socialmente e que aquilo que lhes era próprio, particular, se esvaiu:

"Individuo y sociedad se tornan uno en la medida en que la sociedad irrumpe en los hombres por debajo de su individuación $\mathrm{y}$ así la impide. Que esta unidad, sin embargo, no es una forma superior de los sujetos, sino que los devuelve a un estadio arcaico, se manifiesta en la bárbara represión que en esto se ejerce. La naciente identidad no es reconciliación de lo general y lo particular, sino lo general como absoluto donde desparece lo particular."(ADORNO, 1986. p. 81)

Por meio da reflexão histórica e social, inerente ao método dialético, pode-se compreender a relação entre a esfera psicológica (subjetividade) e social (objetividade) como reciprocamente mediada, tendo-se a subjetividade como fruto de um projeto histórico e paradoxal da civilização ocidental, conforme se disse anteriormente. Essa reflexão, portanto, consiste numa profunda investigação $e$ análise dessa relação e, portanto, na apreensão teórico-conceitual do movimento histórico da própria realidade social, circunscrita em certo tempo e espaço, fruto de determinações históricas. Esse entendimento desemboca não somente numa compreensão (concepção) sobre o indivíduo e as noções que o cercam (como, humanidade, liberdade, autonomia, diferenciação etc.), mas na exigência de uma nova/outra postura (teórico/científica/metodológica/interventiva) frente a ele.

Essa (necessária) postura crítica que desvenda as contradições do indivíduo, da realidade objetiva e da relação entre ambos somente é possível se a própria teoria do conhecimento, sob a forma como vem se constituindo ao longo da história - como mera tecnologia a serviço do capital, puder ser superada por meio da recusa (negação) a tomar parte no jogo ideológico de manipulação e adaptação/integração social dos indivíduos. Esse movimento "quaseque-autofágico" da teoria do conhecimento, não é senão a sua imprescindível autocrítica, sem a qual a transposição dos limites ideológicos que a circunscrevem historicamente dentro de determinados 
"pressupostos de neutralidade $e$ objetividade", orientados por uma racionalidade instrumental (lógica formal) $e$ a demarcam como mera tecnologia, não pode ser alcançada.

\section{Considerações Finais}

Durante as reflexões aqui empreendidas, questionaram-se, de um modo geral, como podem ser apreendidas e analisadas as contradições sociais; como podem ser desvelados os mecanismos $e$ as pressões sociais contemporâneas que subjugam ideologicamente os indivíduos e reforçam seu individualismo, sua crueldade e heteronomia; como se pode romper com a frieza das relações sociais e com a tendência à indiferenciação e à violência vigente na sociedade; e, ainda, como se superar a lógica instrumental e tecnicista que respalda a construção da ciência e da teoria do conhecimento, que são sustentáculos da ordem social moderna e das formas de pensamento e de racionalidade atuantes na sociedade contemporânea.

Diante de tais questionamentos, vislumbra-se a crítica social e a autocrítica como elementos essenciais que devem balizar todo o conhecimento científico, visando à superação de seu mero caráter ideológico e possibilitando o questionamento das condições de existência do objeto e das mediações presentes nos processos atuais de subjetivação/formação dos indivíduos. A necessidade de uma formação reflexiva, iluminada pela lógica dialética presente na teoria crítica da sociedade, torna-se imprescindível, não somente pelo domínio da ciência e da tecnologia em seus fundamentos essenciais, mas porque é esse domínio do conhecimento em suas bases históricosociais que pode possibilitar a compreensão da dialética existente entre sujeito $e$ objetividade e a reordenação da práxis, no sentido da emancipação humana e social dos indivíduos.

Em tempos de "desordem sangrenta" e de "humanidade desumanizada" (parafraseando Brecht ${ }^{13}$ ), como os tempos atuais, torna-se premente que se lance olhar ao processo de formação dos indivíduos, analisando-se criticamente as formas atuais de

\footnotetext{
13“Desconfiai do mais trivial, na aparência, singelo. E examinai, sobretudo, o que parece habitual. Suplicamos expressamente: não aceiteis o que é de hábito como coisa natural, pois em tempo de desordem sangrenta, de confusão organizada, de arbitrariedade consciente, de humanidade desumanizada, nada deve parecer natural, nada deve parecer impossível de mudar". (Bertold Brecht, Nada é impossível de mudar)
} 
sociabilidade $e$ as condições materiais $e$ históricas em que a subjetivação se realiza. Portanto, é, mais do que nunca, válida $e$ atual a discussão adorniana acerca das relações entre subjetividade e objetividade. A apreensão da subjetividade a partir de suas constituintes objetivas implica no entendimento de que o indivíduo não é algo contingente, mas que é historicamente determinado, cujo aspecto social é sua essência, fazendo-se presente nele como objetividade subjetivada.

Sendo assim, o pensamento crítico é essencial ao desvelamento dos elementos hodiernos da formação e ao posicionamento ético e político perante a realidade, visando à transformação das condições atuais de existência.

\section{Referências}

ADORNO, T.W. "Notas marginais sobre teoria e práxis". In: Palavras e Sinais: modelos críticos 2. Trad. de Maria Helena Ruschel. Petrópolis, RJ: Vozes, 1995.

ADORNO, T.W. Educação e Emancipação. Trad. Wolfgang Leo Mar. Rio de Janeiro: Paz e Terra, 1995.

ADORNO, Theodor W. "Acerca de la relación entre sociología y psicología". In: JANSEN, H. Teoría Crítica del sujeto. Buenos Aires: Siglo XXI, 1986.

ADORNO, Theodor W. "Sobre sujeito $e$ objeto". In: Palavras e
Sinais: modelos críticos 2. Trad. de Maria Helena Ruschel. Petrópolis, RJ: Vozes, 1995.

ADORNO, Theodor W. "Teoria de la seudocultura". In: HORKHEIMER, Max; ADORNO, Theodor W. Sociologica. Madrid: Taurus Ediciones, 1971.

ADORNO, Theodor W. A teoria freudiana e o padrão da propaganda fascista. Trad. Gustavo Pedroso. Margem Esquerda ensaios marxistas, $\mathrm{n}^{\circ}$. 7. São Paulo: Boitempo Editorial, 2006.

AMARAL, M.G.T. do O Espectro do Narciso na Modernidade: de Freud a Adorno. São Paulo: Estação Liberdade, 1997.

ANDERSON, Perry. A Crise da Crise do Marxismo: uma introdução a um debate contemporâneo. São Paulo: Brasiliense, 1984 [Coleção Primeiros Vôos].

BATISTA, M. I. F. C. S. A formação do indivíduo no capitalismo tardio: um estudo sobre a juventude contemporânea. Tese de Doutorado, Pontifícia Universidade Católica de São Paulo, São Paulo, 2008.

BATISTA, M. I. F. C. S. "Educação como princípio formativo frente ao preconceito $e$ à violência: reflexões sobre possibilidades $e$ limites de uma educação para a diferenciação na sociedade atual." Comunicações (UNIMEP), v. 22, p. 21-34, 2015.

CANIATO, A.M.P. "A subjetividade na contemporaneidade: da estandardização dos indivíduos ao personalismo narcísico". In: SILVEIRA, A.F. [et al.] Cidadania $e$ Participação Social. Porto Alegre: ABRAPSOSUL, 1999.

CROCHÍK, J. L. "Os desafios atuais ao estudo da subjetividade na Psicologia". Psicologia USP. Vol. 9, n 2, 1998. 
CROCHIK, J.L. "A resistência e o conformismo na mônada psicológica". Psicologia e Sociedade: Revista da ABRAPSO; 13 (2): 18-33; jul./dez. 2001.

FIGUEIREDO, L. C. M. Matrizes do Pensamento Psicológico. Petrópolis - Rio de Janeiro: Vozes, 2008.

FREUD, S. O mal-estar na civilização. Edição standard brasileira das obras psicológicas completas de Sigmund Freud, vol. 21. Rio de Janeiro: Imago, 1996.

HORKHEIMER, Max. "Filosofia e Teoria Crítica". In: HORKHEIMER, Max. (org.) Textos escolhidos. Max Horkheimer e Theodor W. Adorno. Trad. Zeljko Loparic... [et al.] $5^{\mathrm{a}}$ ed. São Paulo: Nova Cultural, 1991(Os Pensadores; 16).

HORKHEIMER, Max; ADORNO, Theodor W. Dialética do Esclarecimento: fragmentos filosóficos. Trad. Guido Antonio de Almeida. Rio de Janeiro: Jorge Zahar Ed., 1985.

HORKHEIMER, Max; ADORNO, Theodor W. Temas básicos de Sociologia. Trad. Álvaro Cabral. São Paulo: Cultrix, 1973.

LÖWY, Michael. Ideologias e Ciência Social: elementos para uma análise marxista. 10ª ed. São Paulo: Cortez, 1995.

SEVERIANO, Maria de Fátima Vieira. Narcisismo e publicidade: uma análise psicossocial dos ideais do consumo na contemporaneidade. São Paulo: Annablume, 2001. 